\title{
Investigation into Korean EFL Learners' Acquisition of English /s/ + Consonant Onset Clusters
}

\author{
Jungyoun Choi \\ Department of English Education, Seoul National University, Seoul, South Korea \\ E-mail: youn4865@snu.ac.kr
}

\author{
Doi:10.7575/aiac.alls.v.7n.2p.48 \\ URL: http://dx.doi.org/10.7575/aiac.alls.v.7n.2p.48
}

Received: $16 / 11 / 2015$

Accepted: 11/01/2016

\begin{abstract}
This paper investigated the phonological acquisition of English /s/ + consonant onset clusters by Korean learners of English as a Foreign Language (EFL) who varied in their levels of proficiency. The data were collected from twenty eighth-graders in a Korean secondary school, who were divided into two groups according to their proficiency: lowand high-achievement. The major findings were: 1) the high-achievement group did not use a vowel epenthesis strategy in the articulation of the $/ \mathrm{s} /+$ consonant onset cluster, unlike the low-achievement group; 2) the duration of $/ \mathrm{s} /$ pronunciation was longer in the high-achievement group, as follows: /s/ + stop + liquid, /s/ + stop, /s/ + liquid; 3) the low-achievement group's duration of oral closure was longer than was that of the high-achievement group, as follows: /s/ + stop + liquid, s/ + stop, and 4) with regard to how /s/ + consonant onset clusters are perceived by native English speakers, /s/ + stop + liquid was related more significantly to the learners' level of proficiency than were the biliteral consonant onset clusters. Among biliteral onsets, /s/ + stop and /s/ + liquid clusters differed significantly between the groups, while the /s/ + nasal cluster did not.
\end{abstract}

Keywords: English /s/ + consonant onset clusters, L1 transfer, the sonority sequencing principle, syllable structure, L2 phonological acquisition

\section{Introduction}

As influenced by two primary approaches, first language (L1) transfer and markedness effects, the question pertaining to how certain phonological structures are produced by second language (L2) learners has been raised frequently. Specifically, with respect to consonant clusters, earlier research of L1 transfer assumed that transfer leads to consonant cluster simplification (Broselow, 1984; Lado, 1957; Major, 2001). Expanding on the conformity with L1 syllable structures, a number of later scholars emphasized that L2 speakers of English simplify consonant clustering to conform to universal linguistic principles (Klove \& Young-Scholten, 2008; Osburne, 1996).

Among consonant cluster types, the segment /s/ is especially noteworthy. /s/ is often regarded as having similar phonetic features across languages that leads to positive transfer (Koffi, 2011). Nonetheless, the pronunciation of /s/ in complex onset clusters is a tremendous challenge for L2 learners of English, because no two languages pronounce complex /s/ onset clusters in an identical manner due to the different phonotactic constraints of languages (Duanmu, 2002; Sperbeck, 2010). This situation also holds true for Korean and English. /s/ appears in a wide array of phonological environments in English, but not in Korean, as the latter does not allow consonant clusters within a syllable. In addition, many of the /s/ distribution patterns in English, unlike those in Korean, violate the Sonority Sequencing Principle.

Thus far, little attention has been given to the way in which L2 speakers of English apply these rules that govern the pronunciations of the English /s/ in complex onset clusters. The majority of the previous literature that has investigated consonant clusters concerns modification strategies, such as consonant cluster deletion and vowel epenthesis. The order of acquisition of English consonant clusters (Yoo, 2004), and gender effects on the articulation of some English consonant clusters (Park, 2008), also have been investigated rarely.

Therefore, this study examined the acquisition of English consonant clusters by Korean EFL learners of English. The study focused on onset in an attempt to determine the differences in acquisition of consonant onset cluster types with respect to the level of L2 proficiency. The research questions addressed were as follows:

(1) Do Korean EFL learners with different levels of English proficiency pronounce complex onset clusters with a wordinitial /s/ differently?

(1-1) Is there a difference in the aspects of pronouncing triliteral onset with word-initial /s/ according to the level of English proficiency? If so, how do learners modify the pronunciation (i.e., s + stop + liquid) according to their level of proficiency?

(1-2) Is there a difference in the aspects of pronouncing biliteral onset with word-initial /s/ according to the level of English proficiency? If so, how do learners modify the pronunciation of each cluster type (i.e., $s+s t o p, s+n a s a l, s+$ liquid) according to their level of proficiency? 
(2) Does the difference in pronunciation by Korean secondary school learners with different levels of English proficiency affect native English speakers' judgment of accuracy in pronouncing complex onset clusters with wordinitial /s/?

\section{Theoretical Background}

\subsection{Cross-linguistic differences in syllable structures}

The concept that "transfer" occurs between L1 and L2 has been one of the most important issues for linguists, and has been regarded as the major source of difficulties for L2 learners (Altenberg \& Vago, 1983; Yavas, 2005). One example of a cross-linguistic difference is the syllable structures of languages. While the basic syllable structure is represented as the combination of a single consonant and a single vowel, i.e., CV, languages can have more consonants and different syllable structures, as shown in Table 1. Korean syllable structures do not allow two or more consonants to occur in the onset of a syllable, while English permits two or three consonants at the beginning of syllables.

Table 1. Comparison of syllable structures of English and Korean

\begin{tabular}{ll}
\hline English Syllables & Korean Syllables \\
\hline CV & CV \\
CVC & CVC \\
VC & VC \\
V & V \\
CVCC & \\
CCVC & \\
CCV & \\
VCC & \\
CCVCC & \\
CCCVC & \\
CCCVCC & \\
CVCCC & \\
CCVCCC & \\
CCCV & \\
\hline
\end{tabular}

The cross-linguistic differences between L1 and L2 syllable patterns are challenging for L2 learners. They tend to use L1 syllable structure patterns in the context of L2 by using vowel epenthesis and consonant deletion to modify consonant clusters (Major, 2001; Weinberger, 1997). Many researchers have claimed that Arabic EFL learners used epenthesis when a target L2 syllable structure is absent in their L1 (Al-Shuaibi, 2006; Broselow, 1983, Kharma \& Hajjaj, 1989); Korean EFL learners inserted a schwa sound between English stop + liquid clusters (Kim, 2002; Tarone, 1980). On the other hand, Anderson (1987) insisted that the frequency of epenthesis or deletion strategy is positively related to the length of onsets. Yet, little was known about the extent to which L2 learners modify different consonant cluster types.

\subsection{Violation of phonotactic constraint: the Sonority Sequencing Principle}

The Sonority Sequencing Principle (SSP) is considered universal, as it applies to a large number of languages. Each phoneme is believed to have a sonority scale that shows the relative phonological prominence of different sounds, as shown in Table 2. According to the SSP, sonority must rise towards the syllable peak at onset. Although English complex onset clusters conform to the SSP in most cases, they violate it in such cases as complex onset clusters with word-initial /s/. The question addressed here is what happens when Korean L2 learners, whose L1 conforms to the SSP, speak an L2 that violates it.

Table 2. The arithmetic of sonority

\begin{tabular}{lc}
\hline Sounds & $\begin{array}{c}\text { Sonority } \\
\text { Scale }\end{array}$ \\
\hline$[\mathrm{a}, \mathfrak{\mathrm { e }}$, ə] $]$ low vowel & 10 \\
{$[\mathrm{e}, \mathrm{o}] \mathrm{mid}$ vowels } & 9 \\
{$[\mathrm{i}, \mathrm{u}, \mathrm{j}, \mathrm{w}]$ high vowels } & 8 \\
{$[\mathrm{r}]$ rhotic } & 7 \\
{$[\mathrm{l}]$ liquid } & 6 \\
{$[\mathrm{~m}, \mathrm{n}, \mathrm{j}]$ nasals } & 5 \\
{$[\mathrm{~s}]$ sibilant } & 4 \\
{$[\mathrm{v}, \mathrm{z}, \mathrm{d}]$ voiced fricatives } & 3 \\
{$[\mathrm{f}, \theta]$ voiceless fricatives } & 2 \\
$\left.\left[\mathrm{t} \int, \mathrm{d}\right]\right]$ affricates & 1.5 \\
{$[\mathrm{~b}, \mathrm{~d}, \mathrm{~g}]$ voiced stops } & 1 \\
{$[\mathrm{p}, \mathrm{t}, \mathrm{k}]$ voiceless stops } & 0.5 \\
\hline
\end{tabular}


The SSP violation and its effect on L2 consonant cluster production have been investigated by several studies (Abrahamsson, 1999; Carlisle, 1991; Davidson, Jusczyk, \& Smolensky, 2009; Eckman \& Iverson, 1993). The results indicated that the sonority distance between consonants can render certain patterns of onset consonant cluster, which abide by the SSP, easier than others, which violate the SSP. Yet, how L2 learners with different levels of proficiency use modification strategies according to varying sonority gaps in consonant clusters has been open to debate in the literature.

\section{Methods}

The study was conducted with twenty eighth-graders in a Korean secondary school. They were divided into two groups according to the results of the TOEIC Bridge ${ }^{\circledR}$ Test, i.e., ten were assigned to a low-achievement group and the other ten to a high-achievement group. All of them had studied English for more than five years in Korea without having lived in an English-speaking country. An independent samples t-test confirmed that the high-achievement group $(\mathrm{M}=$ 165.80, $\mathrm{SD}=11.44, \mathrm{~N}=10$ ) was significantly more proficient than was the low achievement group $(\mathrm{M}=30.90$, $\mathrm{SD}$ $\left.=12.71, \mathrm{~N}=10), t_{18}=24.95, \mathrm{p}<0.001\right)$.

Target consonant clusters (Table 3) were selected in accordance with the classification of the English consonant clusters (Prator \& Robinett, 1985) and the word lists provided in the secondary school English textbooks.

Table 3. Target sonority clusters

\begin{tabular}{|c|c|c|c|}
\hline & & & Target Word \\
\hline $\begin{array}{l}\text { Triliteral } \\
\text { Onset }\end{array}$ & s + stop + liquid & $\begin{array}{l}/ \text { str/ } \\
\text { /skr/ } \\
\text { /spr/ } \\
\text { /spl/ }\end{array}$ & $\begin{array}{l}\text { street, stream } \\
\text { script, scream } \\
\text { spring, spread } \\
\text { split, splendid }\end{array}$ \\
\hline \multirow{3}{*}{$\begin{array}{l}\text { Biliteral } \\
\text { Onset }\end{array}$} & s + stop & $\begin{array}{l}/ \mathrm{sk} / \\
/ \mathrm{st} / \\
/ \mathrm{sp} /\end{array}$ & $\begin{array}{l}\text { skip, school } \\
\text { style, study } \\
\text { spoon, speak }\end{array}$ \\
\hline & $s+$ nasal & $\begin{array}{l}/ \mathrm{sm} / \\
/ \mathrm{sn} /\end{array}$ & $\begin{array}{l}\text { smile, small } \\
\text { snow, snail }\end{array}$ \\
\hline & s + liquid & $/ \mathbf{s l} /$ & slave, slight \\
\hline
\end{tabular}

Two tests, the Production and Perception Test, were implemented to investigate the acquisition of onset consonant clusters. For the Production Test, a Word Reading Task was used, in which the learner participants were given a word list on paper and asked to read the words as naturally as possible. They were allowed first to go through the words for approximately three minutes, and to ask questions regarding any words with which they were unfamiliar. After the recordings were uploaded, the Praat software program (Boersma \& Weenik, 2012) was used to analyze the speech sounds. To identify the cluster and the /s/ boundaries, the onset and offset of /s/ was marked with a boundary where the high frequency energy appeared and ended. The oral closure was marked at the point at which the intensity dropped distinctly, with a loss of energy in the higher formants. During segmentation, if it was difficult to determine a boundary point, the spectrogram display and auditory judgment were used. After the speech was segmented and labeled, the duration of every /s/ and one of the oral closures was measured. All interval durations were also investigated to see whether vowel insertion and epenthesis occurred between consonants and in the starting position of syllables. Together with the acoustic properties of the spoken data, human rating methods were implemented. Four hundred speech tokens (twenty words * twenty subjects), two hundred for the low-achievement group and two hundred for the highachievement group, were presented for rating by two native English speakers who had more than three years of teaching experience and evaluated the recorded data independently. The two native raters also participated in evaluating the Perception Test, and rated the total set of speech data on a 5-point scale where $1=$ "very poor accurate English /s/ + complex onset clusters," and $5=$ "very excellent accurate English /s/ + complex onset clusters."

\section{Results}

\subsection{Production test}

\subsubsection{Vowel epenthesis}

Epenthesis was assessed by scanning the spectrogram and the waveforms visually. The researcher looked for a sharp change in energy at the onset or offset of the clear formant structure, and checked the frequency of the formants by reference to Ramírez's (2006) study to detect the epenthetic vowel. For example, the first, second, and third formants of the epenthetic /i/ had means of 569.17, 1944.00, 3039.95 Hz, respectively. Vowels normally have three different formants that seem to differ from consonants, which appear as noticeable dark bands based on the vowel position.

Three students in the low-achievement group produced vowel epenthesis when a syllable began with /s/ and was followed by a voiceless stop either in triliteral or biliteral onset (compare Figures 1 and 2). For the high-achievement group, vowel epenthesis did not serve as a strategy in the articulation of English /s/ + consonant onset clusters. In addition, there was a significant difference in the /s/ durations, as well as the durations of the oral closure between both groups, which will be discussed in the next section. 


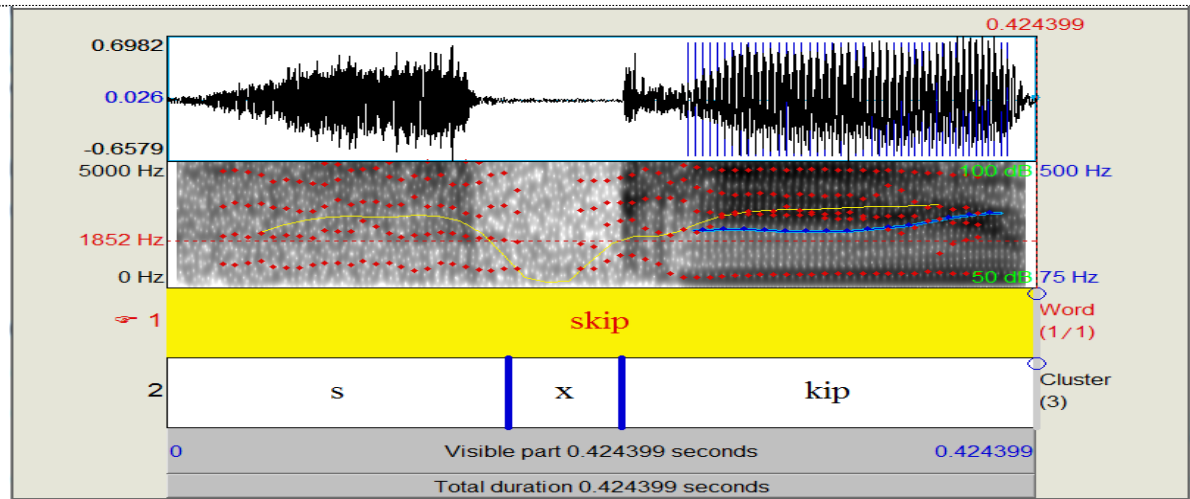

Figure 1. The word skip without vowel epenthesis by a high-achievement student

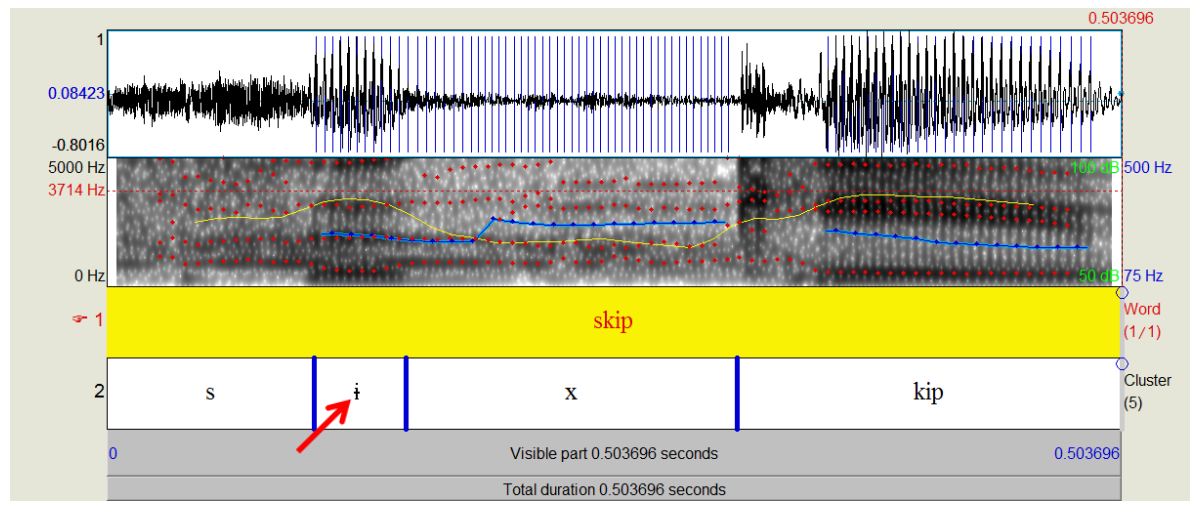

Figure 2. The word skip with vowel epenthesis by a low-achievement student

\subsubsection{Duration of /s/ and oral closure}

The mean durations for both groups were calculated to investigate how the high- and low-achievement groups differed in their production of each type of cluster. An independent sample t-test was conducted to interpret the effects of group differences in the production of /s/ and oral closure. As shown in Table 4, the high-achievement group differed significantly from the low-achievement group in terms of their duration of production of /s/ in triliteral and biliteral onset with word-initial /s/, except /s/ in /s/ + nasal. The duration of pronunciation of /s/ by the high-achievement group was approximately $234 \%(/ \mathrm{s} /+$ stop + liquid $), 52 \%(/ \mathrm{s} /+\mathrm{stop})$, and $12 \%(/ \mathrm{s} /+$ liquid) longer than that in the lowachievement group.

Table 4. Mean /s/ duration (in s) for high and low-achievement groups

\begin{tabular}{|c|c|c|c|c|c|c|c|c|c|c|c|c|}
\hline & \multirow{2}{*}{\multicolumn{3}{|c|}{$\begin{array}{c}\text { Triliteral Onsets } \\
/ \mathrm{s} / \text { in } / \mathrm{s} /+ \text { stop+ liquid }\end{array}$}} & \multicolumn{9}{|c|}{ Biliteral Onsets } \\
\hline & & & & \multicolumn{3}{|c|}{$/ \mathrm{s} /$ in $/ \mathrm{s} /$ + stop } & \multicolumn{3}{|c|}{ /s/ in /s/ + nasal } & \multicolumn{3}{|c|}{ /s/ in /s/ + liquid } \\
\hline & $\mathbf{M}$ & SD & $t$ & $\mathbf{M}$ & SD & $t$ & $\mathbf{M}$ & SD & $t$ & $\mathbf{M}$ & SD & $t$ \\
\hline High & 0.21 & 0.01 & \multirow{2}{*}{$0.000 *$} & 0.17 & 0.02 & \multirow{2}{*}{$0.002 *$} & 0.14 & 0.01 & \multirow{2}{*}{0.122} & 0.14 & 0.01 & \multirow{2}{*}{$0.017 *$} \\
\hline Low & 0.06 & 0.02 & & 0.15 & 0.02 & & 0.13 & 0.01 & & 0.12 & 0.02 & \\
\hline
\end{tabular}

In addition, to determine the quantitative relationship of the /s/ sound to the entire utterance of a target word, the percentage of the duration of /s/ pronunciation was calculated to analyze the association between the students' proficiency and the mean /s/ duration, while controlling each student's latency to pronounce a given target word. The process of calculating the percentage entailed dividing the time taken to pronounce the /s/ sound by the total time taken to pronounce a target word that contained the calculated /s/ sound.

Table 5. Mean /s/ duration (in \%) for high and low-achievement groups

\begin{tabular}{|c|c|c|c|c|c|c|c|}
\hline \multirow{2}{*}{\multicolumn{2}{|c|}{$\begin{array}{c}\text { Triliteral Onsets } \\
/ \mathrm{s} / \text { in } / \mathrm{s} /+ \text { stop+ liquid }\end{array}$}} & \multicolumn{6}{|c|}{ Biliteral Onsets } \\
\hline & & \multicolumn{2}{|c|}{$/ \mathrm{s} /$ in $/ \mathrm{s} /+\mathrm{stop}$} & \multicolumn{2}{|c|}{ /s/ in /s/ + nasal } & \multicolumn{2}{|c|}{ /s/ in /s/ + liquid } \\
\hline $\begin{array}{c}\chi^{2} \\
20.00\end{array}$ & $\begin{array}{c}p \\
0.018 *\end{array}$ & $\begin{array}{c}\chi^{2} \\
20.00\end{array}$ & $\begin{array}{c}\boldsymbol{p} \\
0.029 *\end{array}$ & $\begin{array}{c}\chi^{2} \\
6.53\end{array}$ & $\begin{array}{c}p \\
0.366\end{array}$ & $\begin{array}{c}\chi^{2} \\
20.00\end{array}$ & $\begin{array}{c}\boldsymbol{p} \\
0.045^{*}\end{array}$ \\
\hline
\end{tabular}

As shown in Table 5, the results were similar to those in Table 4. The percentage of the duration of pronunciation of /s/ in the $/ \mathrm{s} /+$ stop + liquid cluster was approximately $38 \%$ for the high-achievement group and $6 \%$ for the lowachievement group. The $/ \mathrm{s} /+$ stop cluster and $/ \mathrm{s} /+$ liquid cluster were approximately $29 \%$ and $39 \%$ for the highachievement group, and $15 \%$ and $29 \%$ for the low-achievement group, respectively. Thus, the percentage of the 
duration of pronunciation of /s/ by the high-achievement group was approximately $533 \%$ (/s/ + stop + liquid), $93 \%$ (/s/ + stop), and 34\% (/s/ + liquid) longer than that of the low-achievement group.

Because the data above showed a significant difference in the /s/ duration between the two groups and the spectrograms demonstrated quite a difference when scanned visually, the duration of the oral closure in the clusters was analyzed further. A significant difference was observed in the mean duration between the high and low-achievement groups when /s/ was followed by a stop sound (see Table 6). Contrary to the results for the duration of pronunciation of /s/ above, the mean duration of oral closure for the low-achievement group was found to be relatively longer than that of the highachievement group. The low-achievement group was approximately $295 \%(/ \mathrm{s} /+$ stop + liquid), and $154 \%$ (/s/ + stop) longer than was the high-achievement group. In addition, when the percentage of the duration of oral closure was calculated, the mean duration of the low-achievement group (38\% for $/ \mathrm{s} /+\mathrm{stop}+$ liquid; $33 \%$ for $/ \mathrm{s} /+$ stop) was also significantly longer than that of the high-achievement group ( $9 \%$ for $/ \mathrm{s} /+\mathrm{stop}+$ liquid; $13 \%$ for $/ \mathrm{s} /+$ stop).

Table 6. Mean duration of oral closure (in s) for the high and low-achievement groups

\begin{tabular}{|c|c|c|c|c|c|c|c|c|c|c|c|c|}
\hline & \multirow{2}{*}{\multicolumn{3}{|c|}{$\begin{array}{c}\text { Triliteral Onsets } \\
\text { Oral Closure } \\
\text { in } / \mathbf{s} /+ \text { stop+ liquid }\end{array}$}} & \multicolumn{9}{|c|}{ Biliteral Onsets } \\
\hline & & & & & $\begin{array}{l}\text { al Clo } \\
/ \mathrm{s} /+\end{array}$ & & & $\begin{array}{l}\text { Clo } \\
/+\mathrm{n}\end{array}$ & & & $\begin{array}{l}\text { losu } \\
\text { liqu }\end{array}$ & \\
\hline & $\mathbf{M}$ & SD & $t$ & $\mathbf{M}$ & SD & $t$ & $\mathbf{M}$ & SD & $t$ & $\mathbf{M}$ & SD & $t$ \\
\hline High & 0.04 & 0.02 & $0000 *$ & 0.06 & 0.05 & $0000 *$ & · & $\cdot$ & & $\cdot$ & & \\
\hline Low & 0.17 & 0.08 & & 0.15 & 0.04 & & . & . & & . & & \\
\hline
\end{tabular}

An example of the findings above is provided below in Figures 3 and 4, which show two pronunciations of the word script. The waveform and spectrogram show clearly that for a student in the high-achievement group, the /s/ is longer and the oral closure is shorter than are those of a student in the low-achievement group.

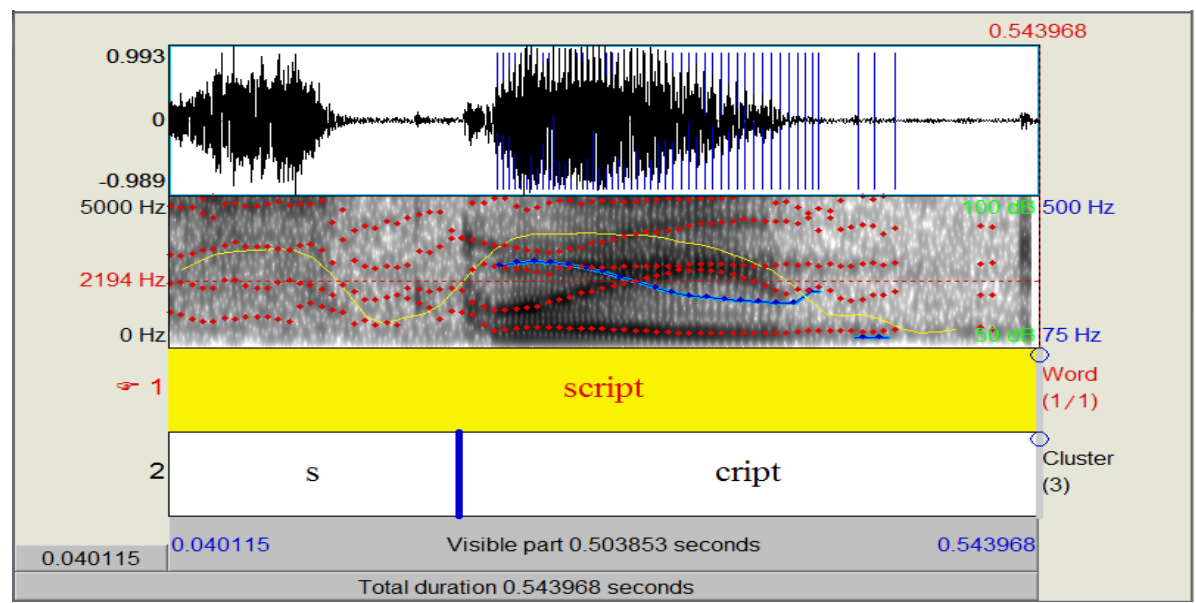

Figure 3. The word script without oral closure by a high-achievement student

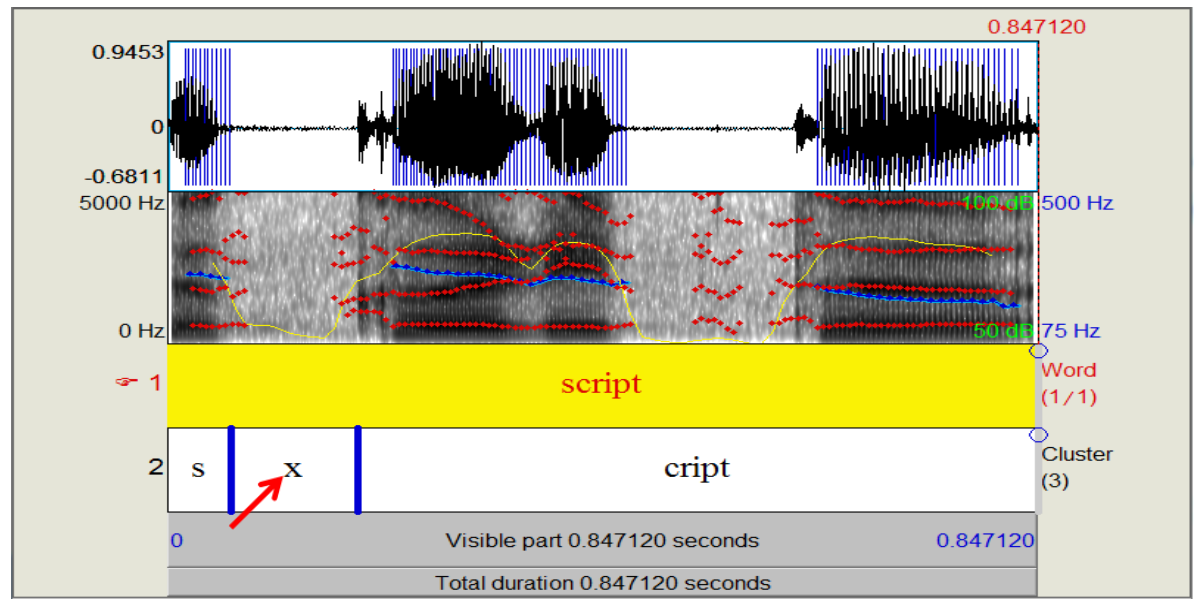

Figure 4. The word script with oral closure by a low-achievement student

\subsection{Perception test}

To test the hypothesis that the difference in pronunciation caused by the proficiency level affects teachers' judgments of accuracy, we examined whether there was any relationship between the score of each English $/ \mathrm{s} /+$ complex onset 
cluster production by the two groups according to their L2 proficiency. With respect to the ratings of the samples, the dependent variable was the mean of the accuracy ratings that were calculated by averaging the two English listeners' ratings for the twenty Korean subjects. When the intra-class correlation coefficient measured the degree of inter-rater reliability for each group of raters' evaluations of the subjects' speech, the raters' coefficients were highly correlated, $\mathrm{r}^{2}$ $=0.90, p<0.001$, thus indicating high levels of agreement among the native English speaking raters. The Pearson ChiSquared statistic was employed for statistical analysis of the association between students' proficiency level and their perception test scores. According to the type of complex onset clusters, either the scores were, or were not, related significantly related to the proficiency levels. Triliteral onset with word-initial /s/ showed a much more significant association $\left(\chi^{2}=17.33, p<0.05\right)$, than did biliteral onset. Among biliteral onsets, the score for the /s/ + stop clusters $\left(\chi^{2}\right.$ $=14.29, p<0.05)$, was the most significantly different, followed by the $/ \mathrm{s} /+$ liquid cluster $\left(\chi^{2}=13.46, p<0.05\right)$. However, $/ \mathrm{s} /+$ nasal clusters $\left(\chi^{2}=5.91, p>0.05\right)$, did not differ significantly.

\section{Conclusions}

The findings overall showed that, compared to biliteral onset, triliteral onset with the word-initial /s/ was associated significantly with the (a) acoustic properties of pronunciation and English proficiency, and (b) ratings and English proficiency. As the syllable structure rules in Korean do not allow two or more consonants to occur in the onset of a syllable, it was presumed that the Korean L2 learners have even more trouble when three consonants rather than two occur at the beginning of syllables. More interestingly, the results of this study are related to biliteral onset with wordinitial /s/. The SSP theory has been adopted by many researchers, such as Carlisle (1991), and Eckman and Iverson (1993), as a theoretical framework to justify consonant cluster production. Because the sonority distance in the /s/ + nasal clusters is smaller than in the /s/ + liquid, the SSP would predict that $/ \mathrm{s} /+$ nasal clusters would be more difficult for Korean L2 learners. However, this study demonstrated that the SSP does not always hold true. The finding that /s/ + stop clusters, among other cluster types of biliteral onset with word-initial /s/, showed the most significant association between the (a) acoustic properties of pronunciation and English proficiency, and (b) ratings and English proficiency, could be explained by the SSP. Yet, in contrast to sonority distance, /s/ + nasal clusters did not differ significantly, while /s/ + liquid clusters did. Here, the well-known phenomenon that many Korean L2 learners have difficulty in differentiating between the /r/ and /l/ sound, which is seen commonly as evidence of negative L1 transfer because Korean lacks the phonemic and phonetic distinctions between [r] and [1] found in English, should be taken into account (Kang \& Ahn, 2013; Kang, 2015). Thus, the reason that learners in the low-achievement group were less proficient in /s/ + liquid clusters than in /s/ + nasal clusters might be relevant to the problematic segment /l/. In addition, the learners who had difficulty pronouncing biliteral onset with word-initial /s/ and a stop sound were found to struggle with triliteral onset with word-initial /s/ (i.e., s + stop + liquid), but not the converse.

The results of this study have many pedagogical implications as the beginning of words is crucial for accurate word recognition and latencies in word recognition of 250-300 milliseconds may cause a continuous breakdown in communication (Byrd \& Mintz, 2010). Among three cluster types, i.e., s + stop, s + nasal, s + liquid, this study suggested that the pronunciation of $/ \mathrm{s} / \mathrm{in} / \mathrm{sk} /, / \mathrm{sp} /$ and $/ \mathrm{st} /$ in onset clusters requires more attention in L2 acquisition studies than do others, such as /sm/, /sn/, or /sl/. In the classroom, L2 teachers should be encouraged to exaggerate the initial /s/ as one pedagogical technique to deal with /s/ in onset consonant clusters (Celce-Murcia et al., 2010; Koffi, 2011). For example, the initial /s/ in words such as, skip, study, and speak can be elongated as /sssskip/, /sssst $\Lambda$ di/ and /sssspi:k/. Further, words like street, script, and spring can be practiced as /sssstri:t/, /sssskript/ and /ssssprin/. More research on English consonant onset clusters is needed to benefit L2 learners of English, and specific materials must be developed to facilitate pronouncing English in a natural and effective way.

\section{References}

Abrahamsson, N. (1999). Vowel epenthesis of /sC(C)/ onsets in Spanish/Swedish interphonology: A longitudinal case study. Language Learning, 473-508.

Al-Shuaibi, A. (2006). Phonological analysis of English phonotactics of syllable initial and final consonant clusters by Yemeni speakers of English (Master's thesis, Malaysia University, Penang State, Malaysia). Retrieved from http:// www.languageinindia.com/nov2009/ganithesis.pdf

Altenberg, E., \& Vago, R. (1983). Theoretical implications of an error analysis of second language phonology production. Language Learning 33, 427-447.

Anderson, J. (1987). The markedness differential hypothesis and syllable structure difficulty. In G. Ioup \& S. Weinberger (Eds.), Interlanguage phonology: The acquisition of a second language sound system (pp. 279-291). Cambridge, MA, Newbury House.

Boersma, P., \& Weenink, D. (2012). Praat: doing phonetics by computer. [Online]

Available: http://www.praat.org/(December 20, 2015).

Broselow, E. (1984). An investigation of transfer in second language phonology. IRAL - International Review of Applied Linguistics in Language Teaching 22, 253-269.

Byrd, D., \& Mintz, T. (2010). Discovering speech, words, and mind. Chichester, West Sussex: Wiley-Blackwell. 
Carlisle, R. (1991). The influence of environment on vowel epenthesis in Spanish/English interphonology. Applied Linguistics, 76-95.

Celce-Murcia, M., Brinton, D., Goodwin, J., \& Grice, B. (2000). Teaching pronunciation: a reference for teachers of English to speakers of other languages. New York, NY: Cambridge University Press.

Davidson, L., Jusczyk, P., \& Smolensky, P. (2009). The initial and final states: theoretical implications and experimental explorations of richness of the base. In R. Kager, J. Pater, \& W. Zonneveld (Eds.), Constraints in phonological acquisition (pp. 321-371), Cambridge, UK: Cambridge University Press.

Duanmu, S. (2002). Two theories of onset clusters. Chinese Phonology 11, 97-120.

Eckman, F., \& Iverson, G. (1993). Sonority and markedness among onset clusters in the interlanguage of ESL learners. Second Language Research, 234-252.

Goldsmith, J. (1990). Autosegmental and Metrical Phonology. Cambridge, MA: Basil Blackwell, Inc.

Kang, S., \& Ahn, H. (2013). An Intelligibility-Based Approach to English Pronunciation Teaching: Evidence of [r] Pronunciation. Language Research 49.3, 631-646.

Kang, S. (2015). The intelligibility-based approach to the pronunciation teaching of English: Experimental evidence of /1/ and /r/ distinction. English Language and Linguistics, 61-81.

Kharma, N., \& Hajjaj, A. (1989). Errors in English among Arabic speakers: Analysis and remedy, London, UK: Longman Publishing Group.

Kim, Y. (2002). Coda cluster simplification and its interactions with other coda processes in Korean, Working Papers of the Cornell Phonetics Laboratory 14, 82-112.

Kløve, M., \& Young-Scholten, M. (2001). Repair of L2 syllables through metathesis. IRAL - International Review of Applied Linguistics in Language Teaching 3, 103-133.

Koffi, E. (2011). The pronunciation of /s/ in complex onset and coda clusters in Somali-accented English. In. J. Levis \& K. LeVelle (Eds.), Proceedings of the second pronunciation in second language learning and teaching conference (pp. 130-143). Ames, IA: Iowa State University.

Ladefoged, P. (2006). A course in phonetics. New York, NY: Thomson-Wadsworth.

Lado, R. (1957). Linguistics across cultures. Ann Arbor: University of Michigan Press.

Major, R. (2001). Foreign accent. Mahwah: Lawrence Erlbaum Associates.

Osburne, A. (1996). Final cluster reduction in English L2 speech: a case study of a Vietnamese speaker. Applied Linguistics, 164-181.

Park, H. (2008). The effect of gender and length of English study on the pronunciation of certain English consonants: A case study of Korean EFL learners. Unpublished B.A. Honours' Degree thesis, Southern Illinois University.

Prator, C., \& Robinett, B. (1985). Manual of American English pronunciation, New York: Holt, Rinehart and Winston.

Ramirez, C. (2006). Acoustic and perceptual characterization of the epenthetic vowel between the clusters formed by consonant+liquid in Spanish. In Manuel D.-C. (Eds.), Selected proceedings of the second conference on laboratory approaches to spanish phonetics and phonology (pp. 48-61). Sommerville, MA: Cascadilla Proceedings Project.

Roca, I., \& Johnson, W. (1999). A course in phonology. Malden, MA: Blackwell.

Sperbeck, M. (2010). The acquisition of consonant clusters by Japanese learners of English: interactions of speech perception and production. Unpublished Ph.D. dissertation. The City University of New York.

Tarone, E. (1980). Some influences on the syllable structure of interlanguage phonology. International Review of Applied Linguistics 18, 139-152.

Weinberger, S. (1997). Minimal segments in second language phonology. In A. James \& J. Leather (Eds.), Second language speech: Structure and process (pp. 263-312). Berlin, Germany: Mouton de Gruyter.

Yavas, M. (2005). Applied English phonology. Malden: Blackwell Publishing.

Yoo, H. (2004). Longitudinal study of consonant cluster acquisition, Studies in Phonetics, Phonology and Morphology 10, 481-503. 